\section{Health of indigenous peoples $^{1}$}

Based on: Pan American Health Organization. Health of Indigenous Peoples. Washington, DC: PAHO; 8 July 1997. (Document CD40/14).

\section{BACKGROUND}

Serious and pervasive inequities are known to exist in health status and health service coverage of indigenous population groups in the Americas. While reliable epidemiologic data on health and illness among the over 43 million indigenous people in the Region are not uniformly available, a variety of studies have demonstrated the following:

- Mortality is 3.5 times higher for indigenous infants in Panama than for other infants (1).

- Twenty percent of indigenous infants in Bolivia die before 1 year of age, and $14 \%$ of the survivors die before reaching school age (2).

- Mortality associated with diabetes is $166 \%$ higher among Native Americans in the United States of America than among the general population (3).

- The 1990 age-standardized death rate from accidents and violence among indigenous people is 81 per 100000 population, compared to 46 per 100000 for the Canadian population as a whole (4).

- Mayan schoolchildren in Belize showed the greatest growth retardation among ethnic groups (5).

- In Honduras, life expectancy is 36 years for indigenous men versus 65 years for all men, and 43 for indigenous women versus 70 for all women (6).

- In Mexico, mortality among indigenous preschool children is $12.8 \%$, as compared to $4.8 \%$ in the national population (7).

- In Guatemala, the maternal mortality rate in the indigenous population is $83 \%$ higher than the national rate (8).

Countries throughout the Region are seeking new approaches for delivery of health services and innovative solutions to health problems in order to address the needs of these vulnerable populations. The challenge of dealing with identifiable problems, such as the ones illustrated above, is compounded by the existence of over 400 different ethnic groups in the Region, with a rich diversity of languages, customs, and beliefs. This heterogeneity precludes use of the same approaches and interventions in all places.

In 1992 the Subcommittee on Planning and Programming of the PAHO Executive Committee proposed that the Organization give more careful 
consideration to the health and well-being of the indigenous peoples of the Americas. In response, in 1993, when the world celebrated the Year of the Indigenous Peoples, the Pan American Health Organization embarked on a joint venture with indigenous peoples to explore how PAHO should respond. A consultation workshop was held in Winnipeg, Canada, in which representatives of indigenous populations, governments, and other groups from 18 countries participated, and its recommendations were incorporated into a proposal. Known as the Health of Indigenous Peoples Initiative, the proposal was subsequently presented to and approved by the Governing Bodies of the Organization (Resolution CD37.R5, attached as an Annex).

Based on recommendations from the Winnipeg workshop, five principles guide the Organization's work with indigenous communities, provide criteria for monitoring, and will serve as the basis for evaluation at the end of the Decade of the World's Indigenous Peoples in 2004: (1) the need for a holistic approach to health, (2) the right to selfdetermination of indigenous peoples, (3) the right to systematic participation, (4) respect for and revitalization of indigenous cultures, and (5) reciprocity in relations.

In 1994, participants in subregional workshops in Santa Cruz, Bolivia, and Quetzaltenango, Guatemala, ratified the principles agreed to in Winnipeg and the goals presented in Resolution CD37.R5. By 1995, a Plan of Action had been established to ensure that the political will expressed by the Member States in the resolution was translated into concrete and sustainable action.

This subject has also begun receiving its due attention at the global level. In 1996 the 49th World Health Assembly adopted a resolution on implementing the Decade of the World's Indigenous Peoples (1994-2004), and the UN Working Group on Indigenous Populations included health as an agenda item. In both cases, work under way in the Region of the Americas was acknowledged for having raised awareness about inequities in health status and access to care.

\section{PROGRESS IN IMPLEMENTATION THROUGH 1996}

To date, work within the Initiative has been concentrated in the following five areas: building capacity and alliances; working with Member States to implement national and local processes and projects; developing projects in priority programmatic areas; strengthening traditional health systems; and disseminating scientific, technical, and public information.
Building capacity and alliances. This area of work was the primary focus of the Initiative prior to development of the Plan of Action in 1995, and it continues to be important as changes to the Plan are identified on the basis of lessons learned in the first three years. Subregional workshops provided training, and promotion efforts identified key people in PAHO offices, ministries of health, and indigenous organizations who would be responsible for implementation of Resolution CD37.R5. PAHO has developed alliances with international indigenous organizations, development banks, UN agencies, and national institutions to work in areas of common interest.

Supporting Member States. PAHO is providing support to the countries' efforts to develop national and local plans, policies, and processes to benefit their indigenous populations. Work in this area is being done in a phased approach, with priority being given to countries with large indigenous populations, in terms of either numbers or proportion of total population. However, all countries receive the benefit of subregional and regional efforts.

From the beginning, efforts have been made to involve indigenous representatives, especially women. Work in the countries has been facilitated by the joint involvement of such representatives along with PAHO Country Offices and national counterparts in the ministries of health, where these have been designated. Progress reports have been prepared by ministry of health or PAHO representatives in 18 countries and will form the basis for published summaries of current and future work.

Developing priority projects. A third area of work is to design and mobilize resources for projects that address priority health problems and vulnerable populations. Based on ongoing consultation with indigenous communities, the Initiative has promoted projects and activities in a number of program areas. The most progress has been achieved in water and basic sanitation, health of indigenous women, mental health, cholera prevention, vaccine-preventable diseases, and involvement of NGOs in health development. There are currently 18 regional programs for which proposals, concrete technical cooperation activities, concept papers, and extrabudgetary projects are at various stages of development.

Strengthening traditional health systems. Part of the challenge in this area is to build closer linkages between the indigenous health system, with 
its many types of health agents and practices, and the official system provided by governments. A majority of the 43 million indigenous persons in the Americas probably do not have true access to basic primary health care offered through government-sponsored programs, because even where such services are physically accessible, there are often financial, geographic, or cultural barriers to their use. Where such barriers exist, communities depend upon traditional and spiritual healers to promote health, prevent illness, and provide treatment for common conditions. Several intercountry projects have brought together traditional healers so they might learn from each other. In some countries, NGOs of traditional healers have been established to address needs for quality improvement and national recognition. Legislative remedies may be needed in cases where healers encounter obstacles to their practice or are blocked from obtaining the products they use for healing. In some groups, the objective is to restore knowledge that has been lost because of past devaluation of traditional practices and lack of interest among the young in becoming traditional healers. In addition, health workers who provide care in multicultural communities need to be educated about indigenous health practices.

Promoting information-sharing and research. The fifth area of work is to identify and develop efficient mechanisms to coordinate, promote, disseminate, and exchange scientific and technical information. Through 1996, 23 documents and publications had been prepared and distributed, and as of April 1997, eight more were in development. A pamphlet about the Initiative and a video in English and Spanish are being disseminated throughout the Region. In 1995, a work group on research met to begin setting priorities and developing collaborative research projects that address priority problems. Three indigenous researchers shared their experience and views; they are among a growing network of scientists who will provide guidance for dealing with the numerous ethical issues which are inherent in the conduct of research.

From the beginning of the Initiative, PAHO has emphasized an intersectoral approach and the need to find partners who will work with it to carry out the Plan of Action or who have complementary plans. In May 1996, the Director of PAHO signed an agreement with the Indigenous Parliament of the Americas. It provides that PAHO will work together with other international parliaments to develop and implement a plan to help countries create a legislative agenda for national health policies, produce legislation that deals with traditional healers and medicinal plants, and encourage legislators to work in other advocacy efforts for indigenous health.

\section{CHALLENGES FACED AND LESSONS LEARNED}

In implementing Resolution CD37.R5 and the Initiative, a number of important lessons have been learned. These lessons will provide criteria for reorienting future work.

Resource mobilization has taken longer than anticipated, and negotiations with donors are ongoing. In the future, PAHO will initially focus on efforts that can be carried out with limited additional resources, encourage programs and countries to allocate small amounts of regular funds, and seek out less traditional donors.

Tracking the interprogrammatic components of the Initiative continues to be a challenge, especially when a more general project includes activities related to indigenous health. Attempts are under way to find better ways to track efforts across programs.

Few countries routinely collect and analyze vital statistics or health service statistics by ethnic group, so it has been difficult to develop good baseline data or to adequately assess the health and living conditions of the indigenous peoples of the Region. Future efforts will be directed at promoting disaggregation of core data by ethnic group, with the goal of detecting and monitoring inequalities in health status and access to health services. Where this is not possible in the short term, substitute indicators will have to be found, such as data for municipalities with $50 \%$ or more indigenous population for comparison with national data.

Insufficient progress has been made in the systematic participation of indigenous individuals and their organizations. Very few countries have established technical government commissions with indigenous representatives, although a number have developed interprogrammatic task forces or commissions in the ministries of health. National indigenous institutes are not always controlled by indigenous groups, and, even when they are, they do not always consider health a high priority.

\section{FUTURE PLANS}

Based on experience gained since 1993, the following four principal areas of work are proposed for 1997-1998: 
Strategic planning and management. This continues to be a critical aspect of the Initiative, in order to ensure that it remains consistent with the principles espoused in Resolution CD37.R5. Countries have had different levels of response to promotion of the Initiative, and progress reports presented by countries through 1996 reflect a variety of efforts. The evolution of the Initiative in the countries is expected to consist of four stages: promotion, initiation, consolidation, and evaluation.

A project, "Toward Health of Indigenous Peoples: Processes and Projects," has been submitted to the Inter-American Development Bank and other donors in order to obtain supplemental funding for the initiation stage in the countries. It also includes support for training of indigenous leaders and for subregional networks led by indigenous groups.

Priority programs. PAHO will continue established priority programs and will develop new areas in which countries have an interest in setting up projects with indigenous communities. An important asset will be a human resources database, with indigenous experts identified for each priority program. Where expertise does not currently exist, training for indigenous professionals will be encouraged, and countries could set aside PAHO fellowships to ensure that expertise is developed in priority areas. Finally, the incorporation of an indigenous health component into more general research projects will be encouraged and resources mobilized. This collaborative approach has already yielded modest success.

Organization and delivery of health services in multicultural communities. Activities will focus on preparing health workers to provide culturally sensitive care and on developing and field-testing guidelines and teaching materials to support this effort. Guidelines for the regulation, legitimization, or legalization of traditional healers will also be developed and disseminated in collaboration with the Indigenous Parliament and other international parliaments. Since many indigenous people live in sparsely populated areas, innovative strategies to provide access to basic public health and clinical services will be identified, systematized, documented, and disseminated through technical cooperation between countries.

Production and dissemination of scientific, technical, and public information. Efforts during 1997 and 1998 will be directed toward presenting information on health and living conditions of indigenous peoples in individual countries, in subregions, and in the Region as a whole. Countries will be assisted in the preparation and publication of documents on indigenous health, and priority programs will produce and disseminate reports of their work and basic program documents. PAHO is currently exploring possible sources of funding and technical support for a series of videos on indigenous culture and health development. The videos will highlight the important contributions of indigenous cultures to health and showcase the variety of innovative approaches that are being developed as part of the Initiative.

PAHO's partners for the Initiative include $\mathrm{UN}$ agencies and the Organization of American States. These partnerships will continue to be important for the mobilization of technical and financial resources at the regional and country levels. Other institutions with expertise in indigenous health will also be sought out.

At its 40th meeting the PAHO Directing Council reaffirmed commitment to the goals of the Decade of the World's Indigenous Peoples and approved the activities proposed under the Initiative for 1997-1998 (Resolution CD40.R6). It also urged the Member States to be persistent in efforts to detect, monitor, and reverse inequities in health status and in access to basic health services for vulnerable groups, including indigenous populations.

Equity is a philosophical underpinning of PAHO's work in public health. As long as some communities have less access to services, a greater burden of disease, and fewer opportunities than others, the goal of health for all will not be realized. Persistent efforts on behalf of the indigenous communities of the Americas will allow the countries to celebrate their shared success at the close of the Decade of the World's Indigenous Peoples.

\section{SINOPSIS}

\section{La salud de los pueblos indígenas}

La Iniciativa de Salud de los Pueblos Indígenas fue lanzada por la OPS en 1993, en observación de recomendaciones emitidas en un taller celebrado en Winnipeg, Canadá. Su propósito es afrontar la desigualdad que existe en el estado de salud y en el acceso a atención sanitaria de las poblaciones indígenas de las Américas. Desde 1993 la Iniciativa se ha centrado en las siguientes cinco áreas de acción: la creación de capacidad de actuación y de alianzas; el desarrollo de procesos y proyectos nacionales y locales; el establecimiento de proyectos destinados a hacer frente a los problemas de salud 
prioritarios; el fortalecimiento de los sistemas de salud tradicionales, y la diseminación de información científica, técnica y sanitaria. Se ha usado un enfoque por fases para introducir la Iniciativa en los países y sus respuestas han sido variadas. Los desafios enfrentados actualmente se relacionan con la movilización de fondos extrapresupuestarios, el manejo de las actividades de diferentes programas y agencias y la representación continua de los pueblos indígenas en los niveles regional y nacional. En el presente informe se examina el progreso alcanzado hasta la fecha y se describen las iniciativas que se adoptarán en el futuro

\section{REFERENCES}

1. Amaris A, Flores C, Mojica J. Mortalidad infantil en Panamá: un análisis de sus tendencias derivadas del censo 1990. Panama: 1992.

2. Asongs (1986), in: Centro de Comunicación y Desarrollo Andino. Los Jampiris de Ragaypampa. Bolivia: 1993.

3. Indian Health Service. Trends in Indian health 1996. Washington, DC: Department of Health and Human Services, Public Health Service; 1996.
4. Ministry of National Health and Welfare, Ministry of Supply and Services. Aboriginal health in Canada. Ottawa: Ministry of Supply and Services; 1992.

5. Government of Belize, Ministry of Education; Pan American Health Organization, Institute of Nutrition of Central America and Panama; United Nations Children's Fund; United Nations Development Program. Closing the gap: national height census of school children in Belize,
1996. Belmopan: Ministry of Education; 1996.

6. Rivas R. Pueblos indígenas y garifunas. Honduras: Guaymuras; 1993: 492 pp.

7. Secretaría de Salud, Instituto Nacional Indigenista. La salud de los pueblos indigenas en México. Mexico City: Secretaría de Salud; 1993.

8. Velásquez L. Mujer maya y salud. Guatemala: 1994

\section{ANNEX}

\section{Resolution CD37.R5-Health of Indigenous Peoples}

The XXXVII Meeting of the Directing Council,

Having seen Document CD37/20 on the initiative "Health of the Indigenous Peoples of the Americas";

Taking into account the recommendations formulated by the participants at the Working Meeting on Indigenous Peoples and Health, held in Winnipeg, Manitoba, Canada, from 13 to 17 April 1993;

Recognizing that the living and health conditions of the estimated 43 million indigenous persons in the Region of the Americas are deficient, as reflected in excess mortality due to avoidable causes and in reduced life expectancy at birth, which demonstrates the persistence and even the aggravation of inequalities among indigenous populations in comparison with other homologous social groups;

Considering the aspiration of indigenous peoples to take charge of their own institutions and ways of life, the need for them to assert their own identity, and the need to respect their rights with regard to health and the environment;

Recognizing the unique contributions that indigenous peoples make to the preservation of ethnic and cultural diversity in the Americas, to biodiversity and a balanced ecology, and, most especially, to the health and nutrition of society;

Emphasizing the need to take a new look at, and respect the integrity of, the social, cultural, religious, and spiritual values and practices of indigenous peoples, including those related to health promotion and maintenance and the management of diseases and illnesses; and

Reiterating the importance of the strategy for the transformation of national health systems and the proposal for the development of alternative models of care at the level of local health systems as a valuable tactical resource and a fundamental requisite for dealing with current problems relating to insufficient coverage, inadequate access, and the lack of acceptance of health services on the part of indigenous populations,

(continues on next page) 
1. To adopt Document CD37/20, which describes the initiative "Health of the Indigenous Peoples of the Americas," and the report of the Winnipeg Working Meeting containing the conclusions and recommendations on which the initiative is based.

2. To urge the Member Governments to:

a) Facilitate the establishment or strengthening of a high-level technical commission or other mechanism of consensus, as appropriate, with the participation of leaders and representatives of indigenous peoples, for the formulation of policies and strategies and the development of activities in the areas of health and the environment for the benefit of specific indigenous populations;

b) Strengthen the technical, administrative, and managerial capacity of national and local institutions that are responsible for the health of indigenous populations with a view to progressively overcoming the lack of information in this area and ensuring greater access to health services and quality care, thus contributing to a higher degree of equity;

c) Implement intersectoral actions, as appropriate in each case, in the areas of health and the environment both in the official sector and through nongovernmental organizations (NGOs), universities, and research centers that work in collaboration with indigenous organizations;

d) Promote the transformation of health systems and support the development of alternative models of care, including traditional medicine and research into quality and safety, for indigenous populations within the local health system strategy;

e) Promote the development of disease prevention and health promotion programs in order to address these problems and the most important areas relating to health of indigenous peoples in their countries.

3. To request the Director, within the limits of available resources, to:

a) Promote the participation of indigenous persons and their communities in all aspects of PAHO's work on the health of indigenous persons;

b) Identify technical cooperation resources within existing cooperation programs and provide support for the mobilization of additional resources at the international and national level for implementation and evaluation of the initiative "Health of the Indigenous Peoples of the Americas";

c) Coordinate the regional effort by promoting the establishment of information and mutual cooperation networks between organizations, centers, and institutions whose activities are concerned with the health of indigenous peoples, organizations, and communities, enlisting the Organization's existing mechanisms, initiatives, and programs at the regional level and in the countries and also seeking the cooperation of other agencies and organizations;

d) Expand the evaluation of living conditions and the health situation to include the indigenous peoples of the Region, with a view to gradually overcoming the current lack of information in this area at both the regional and country level;

e) Promote collaborative research at the regional level and in selected countries on high-priority health issues and health care for indigenous peoples.

(Adopted at the fourth plenary session, 28 September 1993) 